\title{
Population Council Annual Evaluation Report: Opening Futures (Abriendo Futuros) for indigenous girls in Yucatan, Mexico
}

Silvana Larrea

Population Council

Follow this and additional works at: https://knowledgecommons.popcouncil.org/departments_sbsr-pgy

Part of the Demography, Population, and Ecology Commons, Family, Life Course, and Society Commons, Gender and Sexuality Commons, Indigenous Education Commons, International Public Health Commons, and the Medicine and Health Commons

How does access to this work benefit you? Let us know!

\section{Recommended Citation}

Larrea, Silvana. 2020. "Population Council Annual Evaluation Report: Opening Futures (Abriendo Futuros) for indigenous girls in Yucatan, Mexico." Mexico City: Population Council. 


\section{POPULATION COUNCIL}

Ideas. Evidence. Impact.

\section{Population Council Annual Evaluation Report}

Project Title:

Project Period:

Reporting Period:

Principal Investigator: $\quad$ Silvana Larrea, MD, MPH

Population Council

Av. Miguel Ángel de Quevedo 578-2

Santa Catarina, Coyoacán

Mexico City, 04010

Mexico

Project Coordinator: $\quad$ Fabiola Romero

Population Council

Merida, Yucatán

Mexico

Submitted: $\quad$ January 6, 2020 
This evaluation report describes the Population Council's (PC) evaluation activities from December 1 st, 2015 to December 1st, 2019, and future evaluation plans (2019 - 2021), as part of the Abriendo Futuros (AF) project for indigenous girls in Yucatan, Mexico. In the first section we describe the finalized analysis of the impact evaluation of the pilot phase, in the second section we report the progress of evaluation activities, and in the third section we include evaluation future plans for the period December 1, 2019 to November 30, 2021.

This paper is research in progress, is a product of professional research, and represents the opinions of the authors. This paper has not been peer reviewed, and this version may be updated with additional analyses in subsequent publications. Contact: slarrea@popcouncil.org

\section{IMPACT EVALUATION}

The impact evaluation followed a quasi-experimental design based on an endline survey applied to girls in six of the eight intervention communities and three control communities. Results from two intervention communities were excluded from the analysis because they were added to the treatment group midway through the implementation (Cholul and Tipikal). All Abriendo participants in the intervention communities and girls between 10-18 years in the control communities that accepted to answer the survey, were included in the endline survey ( $\mathrm{n}=949)$. Informed Consent and Assent Forms were explained and asked to be signed by parents/tutors and the adolescent girls before the survey. The enrollment period of the study was from July 2017 to August 2017. Spillover effects were controlled by selecting control communities located at a distance far enough from intervention communities. Internal mobility between intervention and control communities was also considered.

For the impact evaluation analysis, all girls between 12 and 17 years of age, that participated in at least $25 \%$ of Abriendo Futuros program sessions in treatment communities and all girls with the same age range living in the three comparison communities were identified and selected, through the participant registry and census carried out in 2016, respectively. We excluded from the analysis observations of girls ages 10, 11 and 18 years, girls whose mother and/or father reported being under the age of 30 and household size that was set at more than 10 members. A total of 174 girls from intervention communities that participated in Abriendo Futuros and a total of 253 girls from control communities were included in the impact evaluation analysis. We used Propensity Score Matching (PSM) to identify changes in the following outcomes: teenage pregnancy and school dropout rates (as main outcomes), and financial literacy, attitudes towards gender norms, sexual and reproductive health knowledge, social capital, and exposure to violence.

\section{Enrollment and attainment}

Throughout the length of the program, 657 girls (44.9\%) attended at least one session; of a total of 1,462 girls living in intervention communities. Teabo and Mayapán had the highest number of enrollees (192 girls and 138 girls, respectively). Tixméhuac had the highest participation percentage increase (93\%) between Module 1 and Module 6, while Tipikal had the lowest (22\%). However, despite the increase in the number of enrollees, only $19 \%$ of adolescent girls had a consistent participation (see Figure 1). The main drop-out numbers presented in adolescent girls between 15 to 18 years. 
Figure 1. Consistent participation among Abriendo Futuros participants.

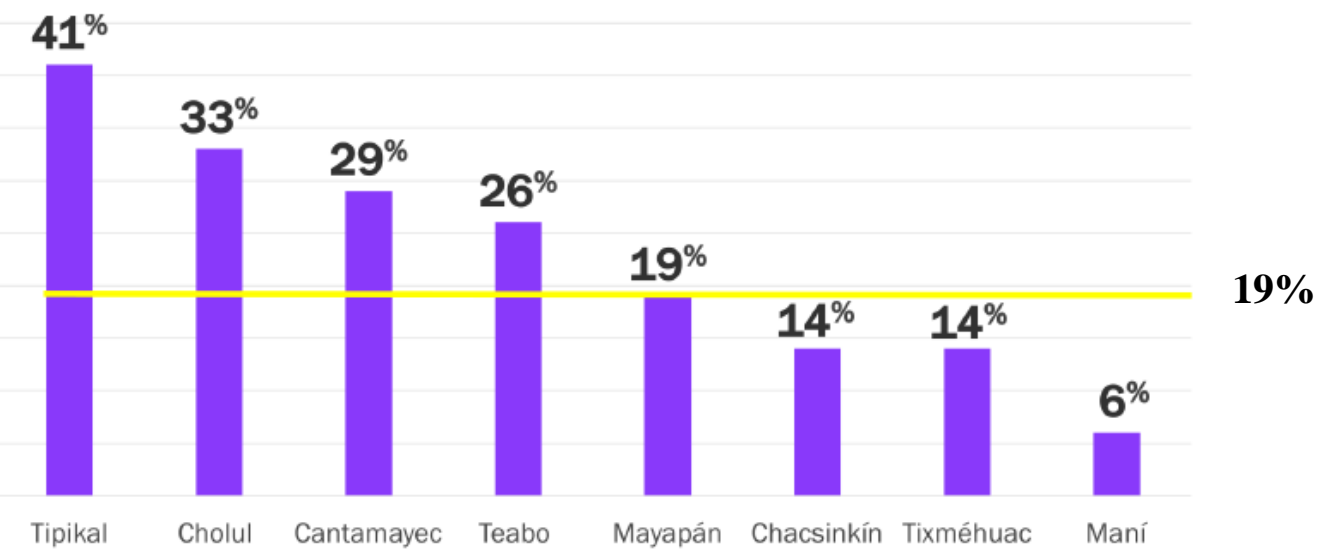

Sociodemographic characteristics: beneficiary vs non-beneficiary households

From the 949 girls that were surveyed at endline, a total of 427 girls (174 beneficiaries and 253 nonbeneficiaries) were selected for the analysis. The median age was 14 years (IQR=13-15) for beneficiaries and 15 years $(\mathrm{IQR}=13-16)$ for non-beneficiaries of the program. The percentage of girls ever married or living with their partner was $1.7 \%(n=3)$ for beneficiaries and $2.7 \%(n=7)$ for non- beneficiaries. No girls participating in AF reported ever being pregnant. In comparison, four non-participant girls reported having a child (1.5\%); however, this difference was not statistically significant between both groups $(\mathrm{p}=0.12)$. Median age at first child for non-beneficiaries was 17 years ( $\mathrm{IQR}=15-17)$. The median age at first marriage was 15 years $(\mathrm{IQR}=15-16)$ for beneficiaries and 16 years $(\mathrm{IQR}=14-17)$ for non-beneficiaries. The median age of girl's partners was 18 years (IQR=16-19) for beneficiaries and 19 years (IQR=19-20) for nonbeneficiaries $(\mathrm{p}<0.10)$. Approximately seven of every ten girls interviewed lived with both their parents. Except for partner age, these characteristics were not significantly different between Abriendo Futuros beneficiaries and non-beneficiaries.

Median age of girls' mothers was 41 years (IQR=37-46) and of girls' fathers was 43 (IQR=38-49). 23.4\% of mothers of non-beneficiary girls did not know how to read and write versus $14.9 \%$ of mothers of beneficiary girls $(\mathrm{p}<0.05) .13 .8 \%$ of fathers of non-beneficiary girls were illiterate in comparison to $15.5 \%$ of fathers of beneficiary girls $(\mathrm{p}=0.62)$. Additionally, mothers of non-beneficiary girls married younger than mothers of beneficiary girls (18 years vs. 19 years; $\mathrm{p}<0.01$ ). In $66.4 \%$ of households of non-beneficiary girls Mayan was the first language spoken at home, in comparison to $57.2 \%$ of beneficiary girls households $(\mathrm{p}=0.05)$. A significantly larger number of inhabitants per house were identified in non-beneficiaries' households versus beneficiaries' households (5 vs. 6; $\mathrm{p}<0.05$ ). A larger percentage of households belonging to the control communities were part of the lowest wealth quintile in comparison to households in the intervention communities ( 24.0 vs. $13.5 ; \mathrm{p}<0.01)$. Due to variations in sociodemographic variables between control and intervention communities, we used the following matching estimators to match participants to non-participants: (1) participant age at endline; (2) work status; (3) exposure to sexual education at school; (4) age of girls' mothers; (5) mother's literacy; (6) mother's highest level of schooling; (7) mother's age at first marriage; (8) father's age; (9) father's literacy; (10) father's highest level of education; (11) Maya as 
primary household language; (12) household size; (13) household socioeconomic status index; (14) and, household position in wealth quintiles.

\section{Impact evaluation results}

Results from the impact evaluation analysis showed significant positive differences $1(\mathrm{p}<0.10)$ in average treatment effect on the treated (ATT) between beneficiary and non-beneficiary girls for motherhood status $(-0.02$ :CI 95\% -0.06-0.00; $\mathrm{p}<0.10)$, having savings in the past three months $(0.20$; CI 95\% 0.07-0.33; $\mathrm{p}<0.01)$, Family Planning Knowledge Index $(0.34$; CI $95 \%-0.00-0.68 ; \mathrm{p}<0.10)$, spending time with friends own age in the past week (0.29; CI 95\% 0.13-0.46; $<<0.001)$, and Social Capital Index (0.63; CI 95\% 0.14 $-1.12 ; \mathrm{p}<0.05$ ) (see Table 1). However, there was not sufficient size to measure program effects on motherhood status, since only four girls $(0.94 \%)$ self-reported having a child. Significant negative differences $(\mathrm{p}<0.10)$ were identified for enrollment in school and educational attainment. No significant differences were found for, ever married or in a civil union, gender norms perceptions, other sexual and reproductive health knowledge indexes, and exposure to physical violence.

Table 1. Average Treatment Effect on the Treated (ATT) of the Abriendo Futuros Program. Impact Evaluation.

\begin{tabular}{|c|c|c|c|c|c|c|}
\hline \multirow[b]{2}{*}{ Motherhood status (has children) } & \multirow{2}{*}{$\frac{\mathbf{N}}{425}$} & \multirow{2}{*}{$\begin{array}{c}\begin{array}{c}\text { Difference B vs C } \\
\text { (ATT) }\end{array} \\
-0.029\end{array}$} & \multicolumn{2}{|l|}{$p$-value } & \multicolumn{2}{|c|}{$\begin{array}{l}\text { 95\% Confidence Interval: Lower } \\
\text { - Upper } \\
\end{array}$} \\
\hline & & & 0.073 & $*$ & -0.060 & 0.003 \\
\hline Ever married or in a civil union & 425 & -0.011 & 0.527 & & -0.047 & 0.024 \\
\hline \multicolumn{7}{|l|}{ Education and Schooling } \\
\hline Enrolled in current school year (2017-2018) & 425 & -0.055 & 0.089 & * & -0.117 & 0.008 \\
\hline Educational attainment (school years) & 425 & -0.330 & 0.068 & * & -0.686 & 0.025 \\
\hline \multicolumn{7}{|l|}{ Financial Literacy } \\
\hline Reports having savings in the past three months & 425 & 0.204 & 0.002 & $* * *$ & 0.074 & 0.334 \\
\hline $\begin{array}{l}\text { Identifies formal institutions as places where girls can } \\
\text { save }\end{array}$ & 421 & 0.058 & 0.119 & & -0.015 & 0.130 \\
\hline \multicolumn{7}{|l|}{ Gender Norms } \\
\hline Desired age for first marriage & 397 & 0.694 & 0.171 & & -0.300 & 1.689 \\
\hline Desired age for first birth & 379 & 0.456 & 0.330 & & -0.461 & 1.374 \\
\hline Desired number of children & 390 & -0.112 & 0.257 & & -0.305 & 0.082 \\
\hline Gender equitable attitudes scale & 395 & 0.195 & 0.679 & & -0.728 & 1.118 \\
\hline \multicolumn{7}{|l|}{ Sexual and Reproductive Health } \\
\hline Puberty and development knowledge index & 419 & -0.076 & 0.589 & & -0.350 & 0.199 \\
\hline Pregnancy knowledge index & 422 & 0.186 & 0.202 & & -0.100 & 0.472 \\
\hline Reports knowing of family planning methods & 424 & 0.006 & 0.930 & & -0.122 & 0.133 \\
\hline Family planning knowledge index & 418 & 0.340 & 0.056 & * & -0.008 & 0.689 \\
\hline Reports knowing of STIs & 423 & -0.017 & 0.832 & & -0.176 & 0.142 \\
\hline Reports knowing of HIV/AIDS & 423 & -0.035 & 0.284 & & -0.098 & 0.029 \\
\hline \multicolumn{7}{|l|}{ Social Capital } \\
\hline \multicolumn{7}{|l|}{ Exposure to Violence } \\
\hline Exposure to physical violence index & 425 & -0.083 & 0.415 & & -0.284 & 0.117 \\
\hline
\end{tabular}

1 Significant positive differences: statistically significant differences in the expected direction between the intervention and control communities. 
Notes: (1) Standard errors are in parentheses. (2) Star values correspond to the following cutoff levels for significance *p=.10, **p=.05, *** $\mathrm{p}=.01$ or better. The highlighted variables in each panel report a significant effect at $\mathrm{p}=.05$ or better.

\section{Discussion}

Adolescence is a critical period in the transition from childhood to adulthood. Empowering girls and keeping them healthy, safe, and in school, as well as developing life skills and a voice in their immediate environment (e.g. family, school, and with their peers), aids in the pursuit of giving adolescent girls a healthy and productive adulthood. Abriendo Futuros follows a similar model to the other Council's girl-centered programming work. These empowering programs for adolescent girls are based on a theory of change developed by the Council (see Figure 2). The framework recognizes that girls cannot create transformational social change by their own and that all empowerment programming for adolescent girls frameworks have to take into account a socio-ecological perspective, situating the programs within families, communities, and countries (1).

Figure 2. Theory of Change for Empowerment Programming for Adolescent Girls. Population Council, 2018.

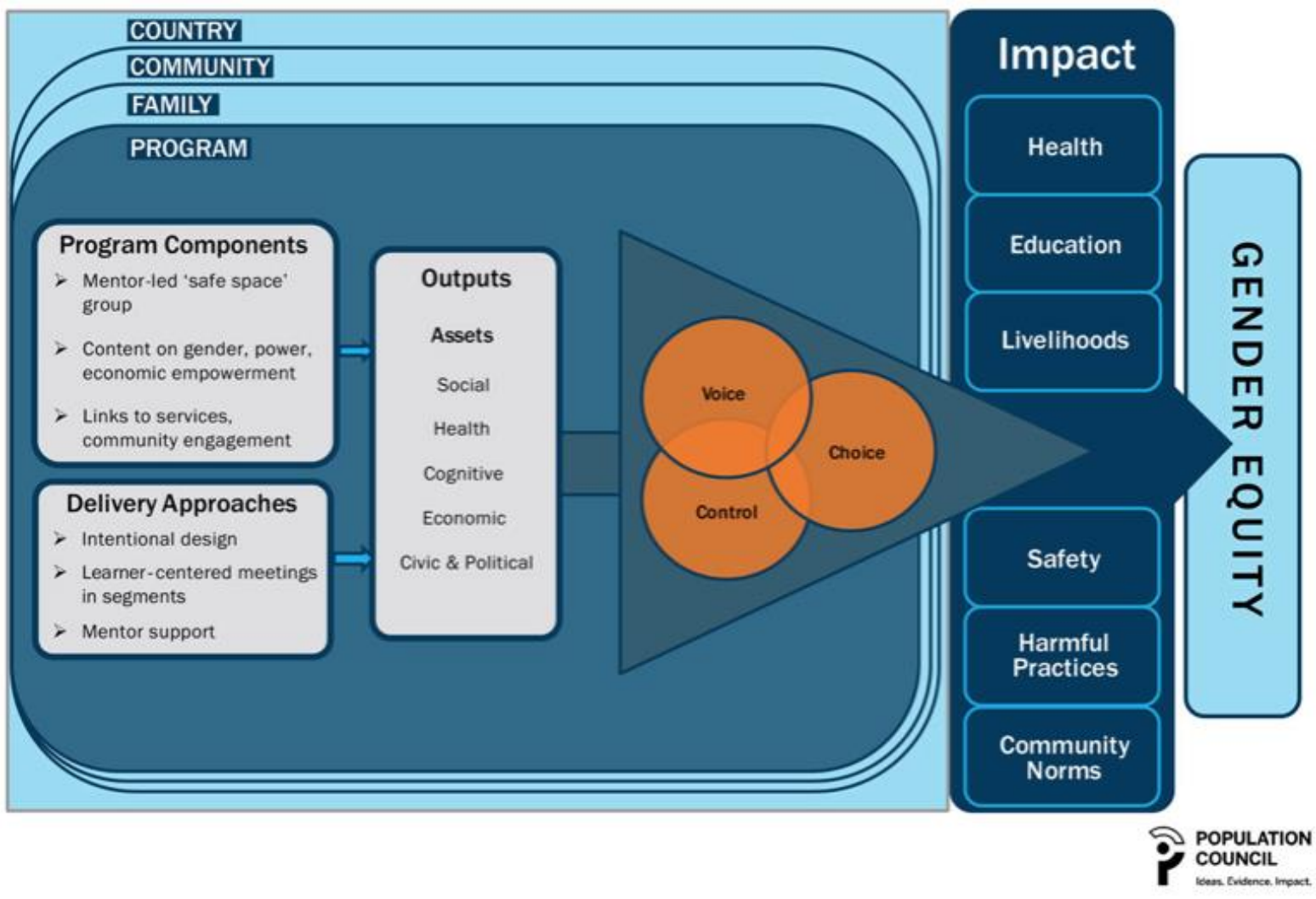

The aim of girl-centered programs based on this theory of change, such as Abriendo Futuros, is work towards buildings girls' protective assets so that girls as individuals and as groups can exercise their voice, choice, and control. Abriendo was successful in developing economic, social, and some cognitive assets (e.g. sexual and reproductive health literacy). However, in order to improve and reinforce the building of protective assets and expand girls' opportunities, girl-centered programs, such as Abriendo Futuros, interventions should (1-3): 
- Have a space only for girls where they can express themselves and share their thoughts and experiences with other girls;

- Be guided by mentors from the same communities as girls. This allows the girls to feel more comfortable learning and sharing their knowledge and allows the mentor to have internal knowledge about prevalent gender norms and social norms that could foster gender-based violence, teenage pregnancy, child marriage, and/or school dropout;

- Interactive, learner-centered, and skill-based teaching approaches should be implemented as the pedagogic proposals for educational interventions;

- If possible, longer-term effects of the program in girls' lives should be measured, for example through longitudinal research;

- Include multi-component curricula, with inclusion of gender and power content;

- Longer program exposure. Evidence shows that this characteristic of programming improves program effectiveness and promote long-lasting effects;

- Theoretical frameworks also show that, due to the multifactorial causes of gender inequalities (including teenage pregnancies and school dropout), muti-level interventions involving the family, school, and community could foster changes in gender and social norms that other programs focusing only on girls could not;

- Including boys and young men into life-skills development programs and gender-based violence prevention programs has also shone benefits for both girls and boys. Boys also live under social norms determined by toxic masculinity types that affects their life-span possibility of choices and shape their attitudes towards women and girls;

- Girls should participate since the beginning in the planning and development of the curricula, so that it responds to girl's needs. This give girls a sense of belonging and personal value; and,

- Before the development of the curricula, researcher should identify and understand the local context and special needs and values embedded in the particular environment. This last recommendation is extremely important for indigenous communities because their perspective differs from western views.

While asset-building girl-centered interventions have shown results in increasing sexual and reproductive health knowledge, financial literacy, social capital, STIs prevention, and contraceptive use, as well as decreasing the likelihood of child or early marriages and school drop-out, there is still little evidence that they have an important impact on other more long-term individual outcomes - such as exposure to violence, early pregnancies, and eventually upward social mobility - and structural outcomes (social and gender norms) (2,3). Nonetheless, there are robust theoretical frameworks on how does improving knowledge and skills, changing attitudes towards unequal social and gender norms, and helping girls develop assets to make better choices could aid (alongside other interventions) in building fairer and more accountable societies for women and girls (1). The improved curricula of Abriendo Futuros second phase is being built based on the findings from the impact evaluation and the formative research.

\section{ABRIENDO FUTUROS SECOND PHASE EVALUATION AND MONITORING PLAN}

Two main activities were considered to be implemented for the second phase of the program: 
I. April to June 2019: a formative research evaluation was conducted in the first trimester of the funding cycle at the school, family, community, and program levels; and,

II. October 2019 to October 2021: a non-experimental pre/post evaluation is underway with participant girls from all eight intervention communities.

\section{Formative research}

Positive, but limited impact in main and intermediate outcomes (such as gender attitudes and exposure to physical violence) was identified through the impact evaluation. To complement these findings, a qualitative assessment was carried out in two of the eight intervention communities (Teabo and Mayapán) on April to June 2019 by an external expert. The results of the evaluation and the qualitative assessment informed the redesign of the program curricula and helped us identify multi-level interventions (e.g. individual, family, and community level) that could potentially aid in achieving improvements in the adolescents' well-being. Data gathering activities carried out and number of individuals interviewed are showed in Table 2.

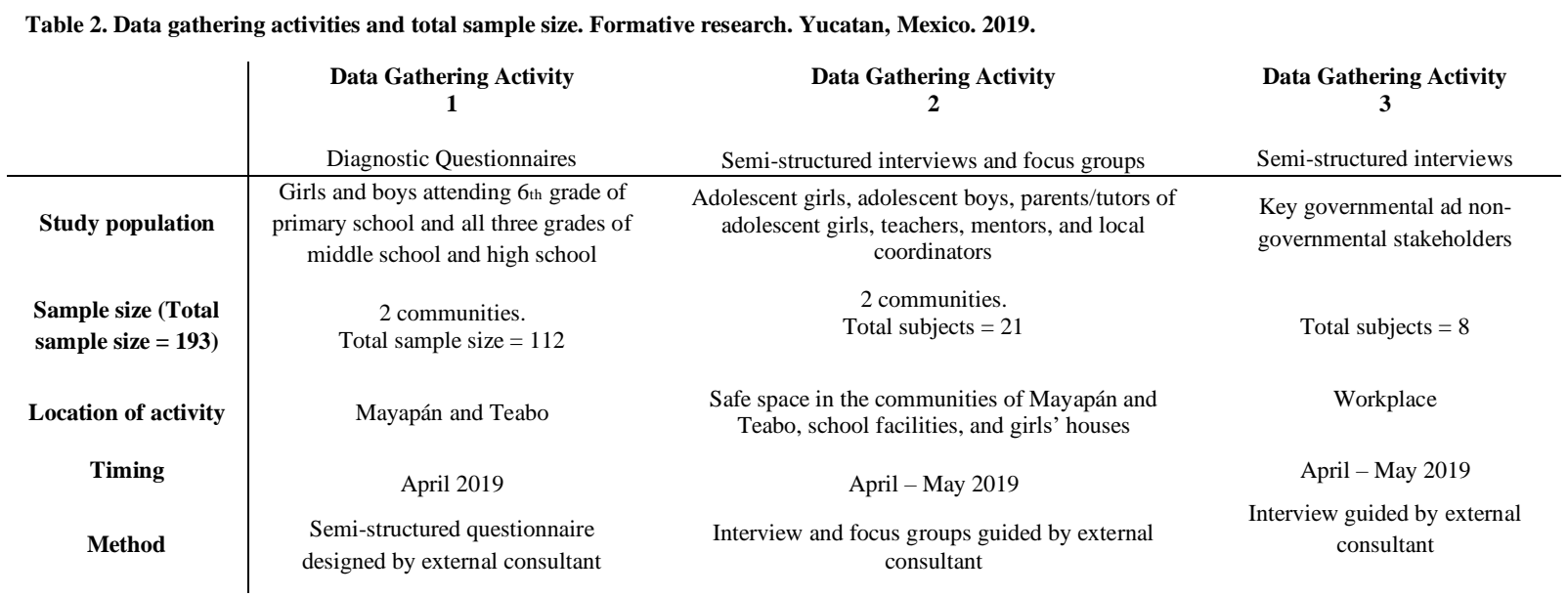

The profile of the students that answered the diagnostic survey was $61.7 \%$ girls and $33.3 \%$ boys with age variating between 10 and 19 years. 52.7\% of participants were enrolled in elementary school, $16 \%$ in middle school, and $31.3 \%$ in high school. 7 out of every 10 participants speak an indigenous language, and $76.8 \%$ identified feeling very proud of being part of the Mayan culture. $20 \%$ of male participants are working and studying versus $5 \%$ of female participants. $83.5 \%$ of male and female participants referred having someone to help them with school activities, and $28.7 \%$ identified having suffered bullying in their schools. $94.8 \%$ expressed their desire of studying a bachelor's degree and only $4.5 \%$ identified ever thinking of dropping out of school. $95.3 \%$ of male participants and $88.2 \%$ of female participants expressed knowing about the importance of school for their futures. The results could show that the reasons for dropping out of school are not linked to the absence of parental support to continue studying or not valuing studies as an asset for their future, but more structural determinants such as poverty and economic needs, lack of intercultural approaches in schools, and very low educational quality that do not give appropriate knowledge and abilities for the future to girls and boy.

Regarding health and psychosocial risks, $6.1 \%$ of participants identified having a family member with mental health problems and $25.6 \%$ referred feeling sad in the last month. Three out of every 10 participants 
identified a family member with alcohol or drug problems and $38.3 \%$ referred that their friends consume alcohol and/or drugs. More female participants (62\%) than male participants (37\%) expressed the need of more information about contraceptive methods and how to obtain them. Also, $60 \%$ of girls versus $50 \%$ of boys referred the need of more information about sexually transmitted diseases (STDs). Both male and female adolescents reported talking most about their sexuality with their mothers (62\%) followed by with their friends $(35 \%)$. In relation to their community, participants expressed their interest to collaborate in communitarian activities to improve the community context (81.4\% of boys and $73.5 \%$ of girls) and identified the following local necessities: scholarships, security, spaces for cultural and sports activities, jobs, increase the quality of healthcare services, artistic and technical schools, public transportation, schools for parents, and accessibility to electricity, water, and food, amongst others.

In the interviews, the mothers and fathers of girls and boys in Mayapán and Teabo expressed the importance of education for their children and the efforts they make to help them continue studying. Mothers identified that their male partners consume large quantities of alcohol during weekends and they are not present in weekdays because they work outside their communities (either in other communities or in the fields). Also, mental health problems were identified by participants as common within their family, and they also noted lack of healthcare resources to address such problems in their communities.

Furthermore, qualitative results suggested that in these communities, school drop-out in middle school is related to different issues: 1) loss of cultural identity when transitioning from an indigenous elementary school to a general middle school as classes are not allowed to be issued in an indigenous language; 2) loss of adequate follow-up given by teachers (in elementary school one teacher is responsible of all subjects while in middle-school each subject is taught by a different teacher); 3) students from indigenous (bicultural) and rural elementary schools have comparatively lower education performance rates than nonindigenous schools mainly because of the lack of professionalization of indigenous teachers as the same teacher has to cover all of the assignments; and, 4) structural factors such as economic needs. Social workers did not mention a specific reintegration strategy for girls and boys that have dropout of school. Another necessity identified in this topic is to increase parent involvement in school related activities.

Finally, we conducted a critical review of Abriendo's curricula and we found that:

1. There is a need to reinforce the curriculum's rights, gender and intercultural dimensions, because they do not fully address the context of inequalities in which AF is implemented. Specifically, these dimensions should be integrated throughout all curricular components and should be used to problematize some situations faced by adolescent girls;

2. There is a need to approach the specific contextual needs from a community development perspective instead of the individual development perspective. Due to the context of deep inequalities present in the intervention communities, we recognize that girls will not be able to foster social change by themselves and that a community development perspective that foster community integration, problem-solving, self-representation, and promotion of collective action will give them a better opportunity of achieving a healthy and productive adulthood versus an individual approach that does not take into account the community as a way of achieving social change;

3. In the pilot phase, the sexual and reproductive health curricula focused on issues related to contraception, risks, and anatomical and biological aspects, and perpetuated heteronormativity. It is important to change this risk perspective to holistic sexual education, that does not focus on reproductive 
aspects only, but also on the significance and experience of sexuality by Mayan girls and adolescent girls from a Mayan vision;

4. Mayan culture has a distinct perspective on gender equity and gender-based violence is sometimes not perceived as a type of violence. Thus, another necessity identified was to approach gender equity and gender-based violence from an intercultural perspective;

5. The formative research highlighted the perceived need of community members regarding mental health. That is why we thought important to integrate mental health and well-being to the AF curricula;

6. The study identified that Maya adolescents do not perceive themselves as rights holders, so it is important to reinforce human rights and civic participation in the improved curricula

7. The predominant teaching method implemented during the pilot phase was a lecture style, which did not allow a comprehensive involvement of girls and adolescents in the learning process and in real life processes (e.g. going to the health center to ask information about contraceptive methods available). A more active learning method is needed to not just learn about topics but also allow girls and adolescent girls to implement the knowledge, i.e. transformative learning

8. Finally, to have a more meaningful impact in the lives of girls and adolescent girls, there is a need to collaborate with other governmental, non-governmental institutions, and local stakeholders and to involve more systematically parents of AGs participating in Abriendo

\section{Pre/post non-experimental evaluation}

Abriendo Futuros curricula and pedagogic strategy were redesigned in order to promote autonomy in Mayan girls and adolescents. We designed a new survey to measure the impact of the improved curricula in the construction of autonomy, while keeping key elements of the endline survey used in the pilot phase. Keeping some of the questions previously asked to girls, allow us to follow-up some of the girls that participated in the pilot phase of AF, and will continue to participate in this second phase. Information from the same girls will be available from 3 different time points: (1) pilot phase endline survey in 2017; (2) second phase baseline survey in December 2019; and, (3) second phase endline survey in September - October 2021. New questions will allow us to measure outcomes that were identified as important in the qualitative study and were not measure previously. Dimensions included in the survey are critical thinking and life skills, financial education, gender, sexual and reproductive health knowledge, attitudes, and practices, citizenship, rights, and sexual and reproductive health, exposure and/or perpetration of violence, mental health, and social capital. Baseline surveys began to be applied to participant girls in all eight intervention communities in December 2019.

\section{Monitoring tools}

With the support of an individual donor, a cellphone app was developed in order to improve the efficiency of monitoring and process evaluation strategies. Pre-existing cellphones from the pilot evaluation phase were given to each of the mentors. Tests and trainings were carried out in September in order to detect any anomaly in the app. Additionally and also with support from the individual donor, six laptops were bought, one for each mentor. Computer skills trainings were delivered during the phase one capacity building workshops to the mentors. As some of the mentors changed, these tools are being taught to the new mentors, mainly Word, Excel, PowerPoint, and internet browsers. Virtual monitoring tools were developed, building 
them from previous experiences in the pilot phase. Every week mentors send to the local coordinator the information gathered through this monitoring tools (attendance spreadsheets and monitoring notebooks).

Until October 2019, a total of 296 girls were registered as participants in the second phase of AF. Communities with the most girls enrolled are Tixméhuac (79 girls), Chacsinkín (53 girls), and Teabo (51 girls). Maní is the community with less girls registered (8 girls). Of the eight intervention communities, five have girls 15 to 18 years registered in the second phase. In total, 66 girls (22.2\%) have between 15 and 18 years.

\section{FUTURE PLANS}

The Abriendo Futuros study is an open cohort, with reliable information from 657 girls since 2017. At endline (2021) we will track down as many girls as possible from the first cohort $(n=657)$ and from the second cohort. With information from repeated cross-sectional surveys, a panel study will be carried out. The main aim of this study will be to identify which risk factors in indigenous girls are most associated to outcomes such as child and early marriages/unions, early pregnancies, school drop-out, and exposure to violence.

We will also implement brief surveys every six months that will monitor risk factors associated to early marriages/unions, early pregnancies, school drop-out, and exposure to violence. Mentors will have previous training and installed protocols on how to refer cases of violence and/or serious mental health problems (e.g. suicide ideation and/or attempt).

Finally, we will conduct a qualitative study with girls, mentors, and parents, at endline, in order to identify the girls' and mentors' perceptions about the curricula, the impact of the program in different dimensions of girls' and mentors' lives, and girls' protective factors against early marriages, early pregnancies, school drop-out, and violence. This information will be used for the triangulation and validation of data obtained from the quantitative assessment.

\section{ACKNOWLEDGEMENTS}

We thank the W.K. Kellogg Foundation for their continued support of our work to strengthen the repertoire of life skills, promote the construction of autonomy, and contribute to improve the quality of life for disadvantaged indigenous adolescent girls in Mexico.

\section{REFERENCES}

1. Temin M, Amin S, Ngo TD, Psaki S. How to give adolescent girls voice, choice, and control. Stanford Soc Innov Rev 2018;1-8.

2. Population Council. Delivering Impact for Adolescent Girls: Emerging findings from Population Council Research, 2018.

3. Haberland NA, McCarthy KJ, Brady M. A Systematic Review of Adolescent Girl Program Implementation in Low- and Middle-Income Countries: Evidence Gaps and Insights. J Adolesc Heal 2018;63(1):18-31. 